Artigo original

Hegemonia - Revista Eletrônica de Relações Internacionais do Centro Universitário Unieuro

ISSN: 1809-1261

UNIEURO, Brasília, número 5, 2010

Recebido em: 26/11/2009

Revisado em: 25/12/2009

Aprovado em: 19/1/2010

\title{
GLOBALIZAÇÃO: A DIALÉTICA DO MULTICULTURALISMO
}

\author{
JUAREZ JUNIOR $^{1}$
}

Resumo: As mudanças no cenário internacional ocorrem de maneira acelerada e contínua, reconfigurando as relações entre os povos constantemente. A partir da compreensão do complexo fenômeno da globalização, o principal objetivo deste artigo é analisar as relações entre os mais diversos atores que compõem o cenário internacional global e contribuir para o debate acerca da questão de identidade cultural nas relações internacionais e na reformulação da identidade dos povos.

Palavras-chaves: Globalização; Multiculturalismo; Brasil.

Abstract: The changes in the international scene occur in sped up and continuous way, reconfiguring the relations between peoples constantly. In an analysis of the complex phenomenon of globalization, the main objective of this article is widely describe the relations between the most diverse actors that make up the international scene and contribute for the debate concerning the cultural identity in the international relations and the reformulation of the identity of nations.

Key-words: Globalization; Multiculturalism; Brazil.

\section{Introdução}

Este trabalho propõe uma reflexão sobre o conceito de globalização, analisando seus desdobramentos na configuração política, econômica, cultural e social do mundo contemporâneo.

1 Bacharel em Relações Internacionais pelo Centro Universitário de Brasília. 
Artigo original

Hegemonia - Revista Eletrônica de Relações Internacionais do Centro Universitário Unieuro ISSN: 1809-1261

UNIEURO, Brasília, número 5, 2010

O objetivo maior do estudo é compreender em que medida a globalização gerou o fenômeno do multiculturalismo, refletindo ainda sobre esse conceito e sobre as consequiências deste fenômeno para o remodelamento das sociedades contemporâneas em meio ao processo de globalização. Busca-se também pensar a questão da ampliação dos diálogos e da diluição de fronteiras culturais decorrente da evolução das tecnologias da informação e sua influência na constituição do fenômeno multicultural.

A questão central do estudo refere-se, portanto, à articulação entre globalização e multiculturalismo, tendo como foco as seguintes indagações:

O que se entende por multiculturalismo e por globalização? Sob o prisma multicultural, que tipo de conflito surge no mundo globalizado e qual a sua relação com a emergência do multiculturalismo? E em que medida, dentre as crescentes interações culturais na era da globalização, a harmonia é capaz de reinar entre as culturas?

Para responder às questões propostas o trabalho será desenvolvido à luz das contribuições de Guiddens (2002); Vesentini (2005); Featherstone (1996); e outros autores, cujas abordagens apresentam importantes formulações acerca do tema.

O multiculturalismo como um fenômeno oriundo da globalização se dá em razão da crescente inter-relação entre os povos vinculada ao aumento no volume de informações, bem como a velocidade com que essas informações são veiculadas atualmente. Daí a importância do estudo para o campo das Relações Internacionais.

O artigo está estruturado da seguinte maneira:

No tópico 1 e 2, com base na literatura proposta, analisamos o conceito de globalização, bem como o surgimento do fenômeno do multiculturalismo como conceito e experiência relacionados ao mundo global. Em seguida, discutimos a questão da diversidade cultural e das relações interculturais surgidas a partir da articulação entre multiculturalismo e globalização. No terceiro tópico serão apresentadas as considerações finais. 
Artigo original

Hegemonia - Revista Eletrônica de Relações Internacionais do Centro Universitário Unieuro

ISSN: 1809-1261

UNIEURO, Brasília, número 5, 2010

\section{A Globalização e Seus Desdobramentos}

"O processo de globalização deve ser visto como a abertura da percepção de que o mundo agora é um só lugar com o inevitável aumento de contato: temos necessariamente maior diálogo entre as nações, blocos e civilizações. Trata-se de um espaço dialógico em que a expectativa é de discordância, conflito e confronto de perspectivas, e não apenas do trabalho conjunto e consenso."

(FEATHERSTONE, 1996:10)

Segundo Gill (apud Gómez, 1997) uma linguagem e um projeto de globalização econômica correspondem a um capitalismo globalizado que tem por espaço natural o próprio mundo e por propósito regular-se sem interferências políticas nacionais, regionais ou internacionais, a fim de gerar benefícios políticos, tecnológicos e econômicos para as nações que nele se inserem competitivamente.

Gómez (1997) trata da globalização econômica como a representação máxima do livre comércio e das garantias internacionais do mercado econômico auto-regulável, tendo como pano de fundo as corporações transnacionais e os mercados mundiais que, uma vez livres das intervenções do Estado, gerarão conseqüências benéficas de prosperidade através dos investimentos, financiamentos, comércio e inovações tecnológicas, além do consumo de produtos baratos e de qualidade.

Em linhas gerais, a melhor estratégia para se alcançar a alta qualidade dos produtos no comércio internacional, consiste no incentivo à livre concorrência. Para tanto, faz-se necessário que haja um conjunto de regras que limitem as ações instituídas pelas corporações multinacionais para que essa concorrência seja leal e forneça mecanismos de eqüidade no mercado internacional. A globalização deve operar exatamente para justificar a co-relação 
Artigo original

Hegemonia - Revista Eletrônica de Relações Internacionais do Centro Universitário Unieuro ISSN: 1809-1261

UNIEURO, Brasília, número 5, 2010

entre a livre concorrência e a eqüidade comercial, possibilitando o alcance de todos os competidores ao lucro gerado pela crescente interação comercial.

Se, por um lado, alguns autores destacam aspectos favoráveis em relação ao processo de globalização, outros optam por enfatizar seus aspectos negativos. Assim, uma das análises possíveis relativas ao processo de globalização econômica no início do século XXI é que ele potencializou o aprofundamento da exclusão econômica e social, principalmente nos países em desenvolvimento, contrariando Robertson (apud Gómez, 1997:134) que afirma no seguinte trecho que "[...] a globalização consiste na compressão do mundo e na intensificação da consciência do mundo como um todo." Portanto, se o mundo globalizado passa a ser visto em sua totalidade e se nenhuma nação busca promover seu próprio subdesenvolvimento e nem acirrar os processos internos de exclusão, as nações deveriam se comportar internacionalmente de maneira que este comportamento resultasse em uma maior abertura à cooperação internacional e investimentos em negociações que gerassem benefícios ao mundo como um todo.

Do mesmo modo, o autor continua sua análise levantando três questões de fundamental importância para a compreensão do processo globalizatório. A primeira delas consiste em afirmar que a globalização não é um processo repentino, mas uma ordem internacional que se compõe ao longo do tempo, tendo como precursores os primeiros navegadores europeus e que, hoje em dia, toma uma nova roupagem com a melhoria das tecnologias da informação.

A segunda questão levantada afirma que as instituições sociais e o povo sofrem os impactos da globalização sem que isso altere necessariamente os padrões de pensamento e significação, traduzindo a idéia de que consciente ou inconscientemente, todos são afetados pelo processo globalizatório, ainda que os resultados ocorram de maneiras distintas em cada sociedade e em cada indivíduo. 
Artigo original

Hegemonia - Revista Eletrônica de Relações Internacionais do Centro Universitário Unieuro ISSN: 1809-1261

UNIEURO, Brasília, número 5, 2010

A terceira e última questão, apresenta o argumento de que é essencial que todos percebam o quanto o espaço foi fundamentalmente comprimido, implicando que indivíduos, organizações sociais e comunidades inteiras se vejam forçados a estabelecer contatos mais próximos e a reconhecerem suas interdependências, seja em âmbito interno, ou no cenário internacional. Mesmo que reconheçamos a existência de centros de controle políticos e de domínio econômico no sistema internacional, sabemos que a relação entre os diversos atores internacionais também ocorre entre a sociedade civil e governos, reformulando as cenas de debate e modificando as relações de poder.

De acordo com Featherstone (1996), no mundo global muitos centros competem entre si, e isso dificulta a probabilidade de que exista um só centro comandando todas as periferias. Fazse notável também que o advento da globalização impõe mudanças consideráveis nas relações de poder entre Estados-Nações e sociedade civil, e ainda entre governos e blocos regionais, gerando novos modelos de interdependência. O autor afirma ainda que a velocidade e expansão dos meios de comunicação, embora não atinjam todos os níveis de composição estatal, e mesmo não assegurando condições igualitárias de acesso a informação, permitem a expansão da atividade da sociedade civil e novos atores, a fim de que estes adquiram poder de barganha no sistema internacional.

Uma das conclusões possíveis sobre o processo de globalização econômica é de que o ideal inicialmente proposto da livre concorrência no mercado internacional ainda precisa ser amplamente trabalhado, pois a já citada exclusão econômica continua sendo o panorama atual deste início de século. Se a idéia de Robertson (apud Gómez, 1997) estiver correta, quando afirma que pensar globalmente é enxergar o mundo como um todo, então o processo da globalização está seguindo a trajetória inversa, caminhando economicamente para a visão individualista, onde impera o egoísmo e o interesse do indivíduo em detrimento do pensamento coletivo. Ou em outra escala, onde interesses de grupos, corporações e Estados 
Artigo original

Hegemonia - Revista Eletrônica de Relações Internacionais do Centro Universitário Unieuro ISSN: 1809-1261

UNIEURO, Brasília, número 5, 2010

prevaleçam diante dos interesses e necessidades de coletividades, comunidades e povos por eles dominados.

Além da dimensão econômica, uma das possibilidades de análise refere-se às dimensões política, social e cultural que configuram o cenário internacional.

De acordo com Held \& McGrew (2001), as relações de poder estão profundamente inscritas na dinâmica da globalização, como é confirmado pelas discussões permanentes sobre suas implicações para o Estado-Nação. Do mesmo modo, os autores sentenciam que desde o policiamento das atividades cotidianas até o provimento da educação e a assistência a saúde, o controle do Estado permanece incontestável, ainda que muitos ressaltem que o fenômeno da globalização veio fragilizar a autoridade e as funções estatais.

Essas constatações revelam, portanto, que a participação do Estado no sistema da globalização ainda é primordial, e gerencia constantemente os processos decisórios nas áreas econômicas e sociais. Entretanto, mesmo em meio à primazia estatal, defende-se que hoje, a participação da sociedade civil seja imperativa no sentido de pressionar os governos a tomarem determinados posicionamentos frente aos mais diversos temas. Ou seja, não vivemos hoje o enfraquecimento do Estado, mas a sua reformulação mediante a proposta de sua democratização via incorporação de atores diversos em suas instâncias decisórias.

Sendo o Estado o exemplo fundamental de marco regulador jurídico internacional, a sociedade civil tem incentivado constantemente os governos a proporem rodadas de negociações em prol dos diversos temas que carecem de atenção na atualidade, como o meio ambiente, a saúde pública, os direitos humanos e das minorias, a exclusão social, a segurança etc. 
Artigo original

Hegemonia - Revista Eletrônica de Relações Internacionais do Centro Universitário Unieuro

ISSN: 1809-1261

UNIEURO, Brasília, número 5, 2010

"[...] o crescimento das organizações e coletividades internacionais e transnacionais, desde a ONU e seus órgãos especializados até os grupos de pressão internacionais e os movimentos nacionais, alterou a forma e a dinâmica do Estado e da sociedade civil. O Estado transformou-se numa arena fragmentada de formulação de decisões políticas, permeada por redes transnacionais (governamentais e não governamentais) e por órgãos e forças internos. Do mesmo modo, a vasta penetração das forças transnacionais na sociedade civil alterou sua forma e sua dinâmica."

(HELD \& MCGREW, 2001: 31)

As negociações têm ocupado cada vez mais espaço na política mundial, e o isolamento já não é uma opção viável para proteger interesses nacionais. Como afirmam Held \& McGrew (2001), os governos nacionais ficam cada vez mais presos ao sistema de governabilidade de múltiplas camadas, em que há esferas de controle local, nacional, regional e global. Alteramse, portanto, as percepções geopolíticas ${ }^{2}$ de que um só Estado seria capaz de controlar diversas políticas globais, e passa-se a reconhecer que decisões mundiais, e até mesmo regionais, estão vinculadas a tomadas de ação conjuntas influenciadas por outros atores, alterando também a percepção de espaço-tempo.

Anthony Giddens analisa a globalização como um fenômeno de

"intensificação das relações sociais em escala mundial, que ligam as localidades distantes de tal maneira que acontecimentos locais são modelados por eventos que ocorrem a muitas milhas de distância e vice-versa. Este é um processo dialético porque tais acontecimentos podem se deslocar numa direção inversa às relações muito distanciadas que o modelam. A transformação local é tanto uma parte da globalização quanto a extensão lateral das conexões sociais através do tempo e do espaço."

(apud GOMÉZ, 1997:136)

\footnotetext{
2 Geopolítica - "Ciência que estuda o Estado como organismo geográfico." (KJELLÉN apud VESENTINI,
} 2005:15) 
Artigo original

Hegemonia - Revista Eletrônica de Relações Internacionais do Centro Universitário Unieuro ISSN: 1809-1261

UNIEURO, Brasília, número 5, 2010

Ainda se tratando de espaço, é imprescindível que se reflita sobre os impactos geográficos das migrações internacionais, fenômeno este reconhecido como um dos frutos da globalização econômica. As mudanças territoriais modificam-se pouco atualmente no que diz respeito às modificações nas linhas fronteiriças, porém, é no tocante à quantidade de pessoas que ocupam os espaços naturais transformando-os em espaços sociais dentro das limitações dos países que se dá todo o processo transformador. Os casos mais graves têm sido nos países desenvolvidos que recebem continuamente imigrantes de países em desenvolvimento, em busca de oportunidades de emprego, sobrevivência e mesmo de enriquecimento financeiro.

"O atual problema demográfico [...] é antes de tudo dos países pobres, e uma de suas prováveis conseqüências, as migrações em massa para regiões ou países ricos, só vai produzir mais intolerância e racismo nestes últimos, criando um clima de discórdia."

(KENNEDY apud VESENTINI, 2005:49)

Situações como a das migrações internacionais precisam ser observadas com cautela, pois impactam drasticamente a economia, a sociedade e a cultura das nações, podendo gerar tanto benefícios quanto prejuízos para a manutenção da ordem interna e política dos povos.

Para tanto, é necessário que se formulem políticas de controle da migração ilegal nas fronteiras dos países aliadas à cooperação internacional, a fim de que o desenvolvimento tecnológico, industrial e social atinja o maior número possível de nações, evitando que haja o fluxo de migração motivada por fatores econômicos, como ocorre ainda hoje.

Por outro lado, o aumento do fluxo de informações influenciou diretamente o crescimento das migrações internacionais, haja vista que, com a invasão de programas televisivos, do marketing agressivo, do capitalismo global e das superproduções cinematográficas produzidas por países desenvolvidos, criou-se nas camadas sociais menos privilegiadas dos países 
Artigo original

Hegemonia - Revista Eletrônica de Relações Internacionais do Centro Universitário Unieuro

ISSN: 1809-1261

UNIEURO, Brasília, número 5, 2010

subdesenvolvidos a expectativa de que estes países oferecem uma mudança radical das condições de vida, de realização pessoal, de consumo e de trabalho.

Segundo Held \& McGrew, muitos dispositivos nacionais de controle da informação tornaramse ineficazes diante do volume a que essas informações chegaram, não obstante à velocidade com as pessoas se comunicam por todo o mundo atualmente. Assim, a percepção do tempo e do espaço vem sofrendo alterações contínuas diante da eliminação de barreiras que suprimiam a livre comunicação até o século XX. "A difusão acelerada das tecnologias do rádio, da televisão, da internet, digitais e dos satélites possibilitou a comunicação instantânea." $(2001: 45)$

O aumento das redes de comunicação modificou consideravelmente a relação entre o espaço geográfico e o homem social, iniciando um mundo virtual em que os interesses comuns de pessoas culturalmente distintas se encontram, mesmo que os cidadãos estejam separados por milhares de quilômetros. Estas redes tomam força pelo fato de agregarem pessoas de várias partes do globo, com poderes aquisitivos variados, de classes sociais distintas, mas que se ligam em torno do mesmo objetivo. Então o homem transforma essas redes em mecanismos eficazes de pressão internacional em defesa de interesses comuns, reconfigurando assim o poder que antes era somente do Estado, e transferindo parte desse poder à sociedade civil. A justificativa para as conclusões anteriores consta da releitura da seguinte afirmação:

"Em resumo [...] a globalização trata da efetiva transformação do espaço e do tempo (a chamada ação à distância, cuja expansão e intensificação recentes relacionam-se com o surgimento de meios de comunicação global instantâneos e ao transporte de massa) [..] a globalização não deve ser equacionada exclusivamente como um fenômeno econômico ou como um processo único, mas como uma mistura complexa de processos frequientemente contraditórios, produtores de conflitos e de novas formas de estratificação e poder, que interpela fortemente subjetividades e tradições, exigindo maior reflexibilidade na ação diante do incremento da complexidade e 
Artigo original

Hegemonia - Revista Eletrônica de Relações Internacionais do Centro Universitário Unieuro

ISSN: 1809-1261

UNIEURO, Brasília, número 5, 2010

da incerteza, e que diz respeito não apenas à criação de sistemas em grande escala, mas também às mudanças nos contextos locais e até mesmo pessoais de experiência social."

(GIDDENS apud GOMÉZ, 1997:139)

Portanto, entende-se a globalização como um processo que afeta desde o ambiente macro ao micro, remodelando as culturas, os estilos de vida e as relações entre pessoas e grupos nas sociedades, desde a esfera pública até a privada.

"Assim, um dos efeitos do processo de globalização - o maior contato e o sentido de finitude do mundo, a consciência de que o mundo é um só lugar - é levar à confrontação de uma pluralidade de interpretações diferentes do significado do mundo, formulado a partir da perspectiva de tradições nacionais e civilizatórias diversas."

(FEATHERSTONE, 1996:22)

Portanto, a complexidade do espaço cultural reformulado pela globalização advém da massificação dos meios de comunicação e da diluição das fronteiras espaciais que limitavam a interação entre as culturas até o século XX.

Segundo Featherstone (1996) a maior dificuldade de se criar um panorama da globalização na atualidade, encontra-se atrelada à composição diversificada das culturas existentes e de suas contínuas modificações e reações quando entram em contato umas com as outras, agindo direta ou indiretamente na vida dos cidadãos ligados a esse processo.

Em resumo, se o processo de globalização atinge inquestionavelmente os campos econômico, físico, político e social, é irrefutável compreender que esse processo tem influência relevante e ocasionalmente determinante na formação e reformulação das culturas locais, regionais e globais. Essa reformulação, por seu turno, vai também impactar os relacionamentos políticos, econômicos e sociais entretidos no cenário mundial. 
Artigo original

Hegemonia - Revista Eletrônica de Relações Internacionais do Centro Universitário Unieuro ISSN: 1809-1261

UNIEURO, Brasília, número 5, 2010

Nesse sentido, uma das peculiaridades do advento da globalização reside na sua articulação com o fenômeno do multiculturalismo, despertado pela massificação da informação, e pela diluição das fronteiras internacionais, reais e virtuais. Além disso, o encontro das diversas culturas em todas as esferas que compõem o cenário internacional vem gerando reações distintas por parte de cada cultura, podendo tanto aproximar os diferentes como causar marcantes choques culturais. A partir de tais diferenças, no tópico seguinte, discutiremos a emergência do fenômeno multicultural, que surge da dialética que o perpassa, qual seja: a de integrar e reunir simultaneamente as diferenças decorrentes das infindáveis possibilidades de diálogos e de contatos abertos e a de consolidar fronteiras e conflitos justamente em virtude de tais aproximações.

\section{O multiculturalismo na Era da Globalização}

“[...] a diversidade cultural é percebida como a integração e não a superposição ou justaposição de culturas e que a sociedade da informação na qual ela se exprime é, antes de mais nada, uma sociedade de conhecimentos compartilhados."

$\left(\right.$ KIYINDOU, 2005) ${ }^{3}$

A identidade cultural é o fator primordial para que grupos sociais se formem e exprimam aos outros seus mais variados pontos de vista sobre os mais diversos temas. Segundo Touraine (1999) o maior exemplo disso é quando se formula a Constituição de uma determinada sociedade, pois nela se refletirá a realidade cultural em que esta sociedade se encontra, buscando ao fim compatibilizar os preceitos defendidos por determinado povo. A coexistência pacífica entre cidadãos de determinada sociedade está ligada à identificação cultural que estes possuem, haja vista que a composição harmônica social necessita que o povo que a constitui

\footnotetext{
3 Citação publicada em artigo de coletânea disponibilizado na internet em: http://vecam.org/article601.html
} 
Artigo original

Hegemonia - Revista Eletrônica de Relações Internacionais do Centro Universitário Unieuro ISSN: 1809-1261

UNIEURO, Brasília, número 5, 2010

esteja minimamente interligado por fatores culturais. Entende-se por fatores culturais, um conjunto de símbolos, crenças e valores compartilhados que orientam a convivência, as relações sociais e as práticas de um grupo ou sociedade. Entretanto, é inegável que intimamente cada pessoa ou grupo tenham inúmeras diferenças quando comparado a outra, sejam elas físicas, psicológicas ou morais.

E é exatamente no tocante às diferenças que o advento da globalização tem exigido no mundo ocidental um novo tipo de atitude e posicionamento que antes era pouco debatido ou inexistente: a aceitação do diferente. A flexibilidade nas relações entre os diferentes, que vem surgindo na sociedade ocidental contemporânea, deve ser de fundamental interesse do Estado, pois as exigências da sociedade civil quanto à maneira de lidar com as diferenças têm crescido progressivamente em paralelo ao processo global, e isso influencia na credibilidade internacional de um Estado. Com o crescimento da participação das Organizações NãoGovernamentais e da sociedade civil no processo decisório estatal, os governos nacionais precisam demonstrar comprometimento com os temas defendidos por esses novos atores emergentes advindos do processo da globalização, pois o grau de confiabilidade e credibilidade em que se encontram as nações atualmente está vinculado às tomadas de decisão de seus governos.

Segundo Touraine (1997), o fortalecimento das instituições nacionais, bem como uma atuação transparente delas afirma o compromisso de um povo com princípios defendidos pela moral ocidental, podendo assim fortalecer a credibilidade de um Estado diante de outros e possibilitando às suas culturas servirem de exemplo a ser seguido por outros povos.

A construção da credibilidade internacional dos Estados se faz também por meio do fortalecimento da unidade nacional que, por sua vez, fortalece os laços culturais que ali existirem, bem como a economia e as instituições que os compõem. Daí a importância do desenvolvimento educacional, pois esse processo gera fortalecimento cultural que, por sua 
Artigo original

Hegemonia - Revista Eletrônica de Relações Internacionais do Centro Universitário Unieuro ISSN: 1809-1261

UNIEURO, Brasília, número 5, 2010

vez, faz-se reconhecer pela mídia que toma cada vez maior espaço na vida do homem por mantê-lo diretamente conectado com o que ocorre em várias partes do mundo. Resultado este que é obtido devido ao advento da globalização. Assim, por intermédio dos processos educacional e midiático - que cada vez mais são globais - as culturas se reformulam.

Acerca da reformulação cultural, Held e McGrew (2001) afirmam que um dos pré-requisitos indispensáveis para a sobrevivência das civilizações e para sua evolução, é renovarem-se, e transcenderem os limites físicos que estejam impedindo seu progresso. O contato cultural é fundamental para que os povos sintam a real necessidade de preservarem-se alguns costumes e excluírem outros. $\mathrm{O}$ encontro de múltiplas culturas que possuam algumas similaridades pode resultar na fusão de inúmeros costumes que se complementem sintetizando o melhor que essas culturas possuem. Porém, quando as culturas possuem valores destoantes em demasia, quando a ética de uma não é compatível a da outra, o embate entre elas pode gerar conflitos de extremo risco à vida humana.

Enfim, as diferenças resultantes da multiplicidade e das inúmeras possibilidades de existir em elevado nível de interação, é que geram o fenômeno do multiculturalismo.

De acordo com McLaren (2000), o multiculturalismo representa a manifestação do híbrido, mas não a simples mistura entre as culturas e sim o conjunto de práticas culturais diversas que compõe uma mesma sociedade. $\mathrm{O}$ autor afirma ainda, que a manifestação das diversidades culturais também é uma representação possível do multiculturalismo, desde que ocorra de maneira pacífica e legítima. Por fim, cita que o mundo multicultural produz novas formas de identidade política e cultural.

Uma das análises de maior relevância sobre o multiculturalismo ocorre acerca da intensificação das relações entre culturas, de maneira que esse encontro pode tornar-se turbulento caso não haja a prática do livre debate e do respeito à alteridade. A história reforça 
Artigo original

Hegemonia - Revista Eletrônica de Relações Internacionais do Centro Universitário Unieuro ISSN: 1809-1261

UNIEURO, Brasília, número 5, 2010

de maneira contundente esses encontros citados: Cristãos versus Muçulmanos; Oriente versus Ocidente; Norte versus Sul.

Se o processo de globalização gerou o fenômeno multicultural e a emergência de sincretismos diversos em nível local, nacional e internacional, o que vem desencadeando uma série de conflitos políticos, econômicos e culturais, certamente isso se deu em virtude de alguns "laços culturais" constituídos e fortalecidos por determinadas sociedades ao longo de sua história.

Tais laços comuns foram consolidados ao longo do tempo, segundo Ortiz (1996), a partir da subordinação de diferenças culturais e 'localismos' a uma realidade maior, a qual se deu o nome de nação. Assim, o passo fundamental para a formação da identidade cultural de um povo e para a constituição de um núcleo conciso e coerente de comportamento cultural que seja capaz de definir o caráter de um povo, foi dado no processo de consolidação do EstadoNação.

Para Ortiz (1996), a composição da nação só se dá com o advento da modernidade e da sociedade industrial, pois com a circulação de cidadãos, de mercadorias e de idéias, as antigas formações feudais mudam para sociedades industriais que respondem a um centro: o EstadoNação. Para que exista uma nação, os indivíduos não devem ser considerados como agentes locais, mas se enxergarem como parte de um todo social amplo que se ligará principalmente por fatores econômicos, lingüísticos e culturais.

Enfim, para o campo das ciências sociais há um consenso de que a nação, dentre suas mais diversas acepções, pode ser percebida como a ligação natural entre os indivíduos que formam e mantém determinada sociedade, seja por meio de línguas, religiões, territórios ou costumes (cultura). Em uma representação mais ampla, a nação pode ser considerada a união dos indivíduos em prol de uma existência coletiva que transpasse os níveis territoriais ou de contato direto entre estes (nação indígena, nação européia, nação latino-americana). 
Artigo original

Hegemonia - Revista Eletrônica de Relações Internacionais do Centro Universitário Unieuro ISSN: 1809-1261

UNIEURO, Brasília, número 5, 2010

As variadas nações existentes no sistema internacional atual configuram um poderoso cenário de cooperação e também de conflito, como afirma Featherstone (1996). Enquanto a cooperação busca os fins convergentes que traduzam o maior lucro possível para todos os seus membros, o cenário conflituoso tende a resultar na destruição de uma determinada cultura em detrimento de outra. O crescente fluxo de informações e de comunicação entre os povos contribui para o acirramento das relações conflituosas entre povos historicamente considerados inimigos, pois configura uma situação de contato constante e de influência direta em assuntos antes considerados internos dos países.

A tensão gerada pela massificação da informação e da comunicação informal entre as nações exprime um desejo contínuo individual de imprimir sua cultura sobre a cultura do outro. Diante da ameaça de extinção de determinada cultura, o homem busca reagir sob a égide da autodefesa, empregando meios de perpetuar sua cultura ou pelo menos eliminar a de seu oponente.

Goméz (1997) argumenta que o caráter volumoso que as informações adquirem no mundo global parece, por vezes, significar que as nações estão se homogeneizando, como se passasse a existir uma maior congruência de objetivos por parte das nações no cenário global, mas factualmente o sinal de maior expressão observado é a disparidade entre culturas e o crescimento de blocos reais e virtuais de comunidades inteiramente multiculturais e independentes, que por muitas vezes divergem de interesses entre si.

De acordo com Held \& McGrew (2001) uma das mais graves crises que a globalização e suas variadas formas de exclusão podem criar é a supressão das minorias, sejam elas culturais ou institucionais. Quando o indivíduo deixa de falar por si só e de construir sua própria cultura, perde a identidade que o liga a sociedade a que pertence. Quando um grupo perde sua capacidade de se pronunciar diante de seu governo, há uma reconfiguração cultural, que por 


\section{Artigo original}

Hegemonia - Revista Eletrônica de Relações Internacionais do Centro Universitário Unieuro ISSN: 1809-1261

UNIEURO, Brasília, número 5, 2010

vezes modifica a estrutura que levou décadas para ser construída e que passa a não se reconhecer como identidade uniforme de uma sociedade.

Como já citado anteriormente, a revolução das tecnologias de comunicação interliga os povos de tal forma que novos atores surgem com força expressiva no cenário mundial, reduzindo as fronteiras internacionais e facilitando o acesso a informação e a cultura de um número maior de indivíduos e classes sociais. Segundo Featherstone (1996), a influência que esses novos atores transnacionais têm na renovação cultural, em consonância com a evolução tecnológica, é de fundamental importância para assegurar a sobrevivência de culturas que há muito tempo pareciam estar em total decadência, caminhando para o seu fim.

“Os Estados que procuram adotar políticas rígidas, de portas fechadas, no que concerne à informação e à cultura, por certo ficam ameaçados diante desses novos processos e tecnologias da comunicação, e é provável que a condução da vida socioeconômica em toda parte também seja transformada por eles."

(HELD \& MCGREW, 2001:46)

A anarquia ${ }^{4}$ a que o sistema internacional está submetido representa um espaço não-físico em que toda atitude tomada por um ator gera reação por parte dos outros, pois o sistema anárquico não reconhece autoridade central de poder. Estima-se que a globalização aproximará as nações a fim de que todas tenham um ponto de vista mais ou menos convergente, a exemplo da busca pela paz mundial. No entanto nota-se, em primeira instância, o fortalecimento da identidade nacional de cada país. Talvez no futuro haja a probabilidade de

\footnotetext{
$4 \quad$ Anarquia: Falta de governo ou de chefe; estrutura social em que não há tutela governamental. Síntese do verbete 'Anarquismo'. (BRAVO. In: BOBBIO, N., MATTEUCCI, N., PASQUINO, G. - Dicionário de Política.)
} 
Artigo original

Hegemonia - Revista Eletrônica de Relações Internacionais do Centro Universitário Unieuro ISSN: 1809-1261

UNIEURO, Brasília, número 5, 2010

que ao serem considerados os interesses de cada nação, a cooperação se torne fator mais comum entre povos de culturas tradicionalmente similares.

Retomando a análise da vertente econômica da globalização, é possível fazer uma releitura deste processo, na medida em que a economia global auxilia a construção de novos conceitos de cultura, como por exemplo, a cultura do consumo, que transforma drasticamente o comportamento social de determinadas civilizações. Os processos de exclusão econômica e social enfraquecem as representações culturais dos povos, bem como a educação e a renovação dessa cultura.

A contínua influência dos países classificados como economicamente desenvolvidos (em sua maioria, ocidentais) sobre os periféricos não pode ser desconsiderada ao se analisar o poder cultural exercido sobre as mesmas proporções econômicas. $\mathrm{O}$ avanço tecnológico e institucional advindo do processo de globalização somado ao poder exercido pelos países do norte exibe a situação de controle que eles possuem no sistema internacional e suas conseqüências nas mutações culturais sofridas pelos países do sul e sua intensa diversidade cultural. E não somente existe a influência norte-sul, mas em casos como o da antiga Federação da Iugoslávia, chega-se ao extremo de cometer crimes para eliminar uma cultura em detrimento de outra, seja para adquirir seu território, seja para exibir uma ilegítima superioridade, conforme ressalta Nogueira (2000). Os prejuízos causados pelos crimes que são cometidos em nome da sobrevivência de determinadas culturas são incalculáveis. $\mathrm{O}$ genocídio $^{5}$ é um destes crimes, e ocorre freqüentemente entre os países que se enfrentam diretamente por motivos culturais.

Em meio às considerações acerca da convivência cultural, outro tema fundamental e complexo é o debate entre a segregação e o sincretismo cultural, entendidos como fatos

5 Genocídio: Destruição metódica de um grupo étnico, pela exterminação dos seus indivíduos. Síntese do verbete “Genocídio”. (LEMKI apud BIANCHI. In: BOBBIO, MATTEUCCI, PASQUINO. - Dicionário de Política.) 
Artigo original

Hegemonia - Revista Eletrônica de Relações Internacionais do Centro Universitário Unieuro ISSN: 1809-1261

UNIEURO, Brasília, número 5, 2010

instigadores e dialéticos. Convém ressaltar que "segregação" é aqui usado no sentido de separação cultural, quando duas ou mais culturas se afirmam distintas e não aceitam dividir um mesmo espaço. Já o "sincretismo" é o oposto, trata de duas ou mais culturas distintas que interagem constantemente a fim de absorver o melhor de cada uma e transformar isto em benefício para o progresso de todos. Portanto, nota-se que há países fronteiriços que possuem culturas e línguas completamente distintas e convivem em harmonia estável há séculos, enquanto outros vivem em constante conflito com suas próprias origens. Existem ainda, países que reúnem culturas em considerável nível de diversidade, que além de conviverem pacificamente, por vezes cooperam entre si.

Semprini afirma que a diferença é uma das questões fundamentais do multiculturalismo, e é crucial aprender a lidar com ela na busca pela harmonia entre os povos e culturas, pois viver em paz com o diferente representa um exercício infindável de compreensão e demonstra um elevado nível de consciência civilizatória. Do mesmo modo, o autor acrescenta que o multiculturalismo imprime questões mais profundas do que o debate acerca das diferenças, citando como exemplo a "capacidade de um sistema social integrar uma diferença autêntica, que não seja comandada 'por cima', nem 'pasteurizada' para se tornar digerível." E finaliza seu texto com a seguinte constatação: "Mais que um desafio social e político, mais que um desafio teórico e filosófico, trata-se de um verdadeiro desafio de civilização que nos é lançado pelo multiculturalismo." (1999:173)

\section{Considerações Finais}

O objetivo principal desse artigo foi o de propor uma reflexão acerca dos conceitos de multiculturalismo e globalização, bem como de seus desdobramentos nos mais diversos campos sociais no mundo contemporâneo.

O estudo se propôs ainda a compreender a globalização nas diversas esferas que compõem o cenário internacional, trazendo discussões acerca das novas relações econômicas ocidentais, 
Artigo original

Hegemonia - Revista Eletrônica de Relações Internacionais do Centro Universitário Unieuro ISSN: 1809-1261

UNIEURO, Brasília, número 5, 2010

como a questão do desenvolvimento e as relações capitalistas entre as nações do ocidente. $\mathrm{O}$ artigo procurou investigar também as práticas políticas e sociais que vem se reformulando com o advento das redes instantâneas de comunicação, considerado fenômeno oriundo da globalização.

Além disso, o artigo se esforçou em estabelecer, a partir desse contexto, uma conexão entre Estado-Nação e Sociedade Civil e o remodelamento das relações de poder entre eles. O surgimento de novos atores no cenário global também foi contemplado pelo trabalho na medida em que a discussão é fundamental para o fortalecimento da percepção de que o "braço" do Estado não alcança todas as áreas de interesse da sociedade, e que esses novos grupos atuarão intensamente no século XXI em busca de maior apoio internacional para solucionar os problemas que serão levantados por eles, seja em âmbito local, regional ou global.

O debate acerca das novas formulações geográficas e geopolíticas foi enfatizado nesse artigo por estar diretamente ligado às questões da pobreza e do desenvolvimento, temas que norteiam as inúmeras conferências mundiais realizadas no fim do século XX e início do XXI. Dentre os pactos de inquestionável importância internacional, encontra-se a Declaração do Milênio $^{6}$, pacto internacional para a eliminação da pobreza, firmado no ano 2000 por 191 países, pacto este que tem 8 macro-objetivos que, dentre outros, buscam erradicar a extrema pobreza e a fome, promover a igualdade entre os sexos e a autonomia das mulheres e estabelecer uma parceria mundial para o desenvolvimento.

A diversidade de conferências realizadas pela Organização das Nações Unidas foi primordial para o surgimento de novos debates regionais e locais sobre as inúmeras situações que transcendem as culturas e seus limites geográficos.

\footnotetext{
6 Referência: Objetivos de Desenvolvimento do Milênio. Relatório Nacional de Acompanhamento.
} (Coord.: Ipea e SPI/MP - PRESIDÊNCIA DA REPÚBLICA DO BRASIL, 2007) 
Artigo original

Hegemonia - Revista Eletrônica de Relações Internacionais do Centro Universitário Unieuro ISSN: 1809-1261

UNIEURO, Brasília, número 5, 2010

Dentre os inúmeros fenômenos surgidos a partir da globalização, este artigo conferiu enfoque especial ao multiculturalismo, cujas peculiaridades são fundamentais para o campo das relações internacionais, pois a cultura forma a base do diálogo travado entre os diferentes povos que se encontram em rodadas de negociações, bem como empresas transnacionais e organismos internacionais em seus campos de atuação.

O fenômeno multicultural foi abordado de maneira a enriquecer a discussão acerca da convivência intercultural, analisando as novas interações advindas da globalização, bem como as exigências que recaem sobre as sociedades ocidentais em relação à aceitação das diferenças. O trabalho propôs ainda uma reflexão sobre os conflitos surgidos a partir da convivência cultural, pois muitos pensadores de Relações Internacionais do século XX já percebiam que os choques que marcariam o terceiro milênio seriam ocasionados por motivos religiosos e culturais. ${ }^{7}$

No entanto, este artigo se propôs a discutir quais as medidas cabíveis para que as interações culturais sejam capazes de configurar um cenário de maior cooperação e aceitação das diferenças. Com base nos autores estudados, foi possível compreender que o multiculturalismo, como fenômeno da moderna globalização em consonância com o advento das tecnologias da informação, desencadeou mudanças consideráveis no cenário internacional dos anos 1990 até os dias atuais. Podemos citar como exemplo de mudanças, as inúmeras conferências dos últimos 20 anos e o crescimento da participação da sociedade civil no processo decisório das instâncias governamentais.

O debate primordial acerca do multiculturalismo foi aqui apresentado como expressão do sincretismo cultural global que, embora caracterizado como tipicamente ocidental, pode ser estimulado de modo a desenvolver processos de interação cultural e de cooperação técnica entre as nações, aproximando os povos e exercitando o diálogo das diferenças.

$7 \quad$ Ver: $O$ Choque das Civilizações e a Recomposição da Ordem Mundial (HUNTINGTON, 1997). 
Artigo original

Hegemonia - Revista Eletrônica de Relações Internacionais do Centro Universitário Unieuro ISSN: 1809-1261

UNIEURO, Brasília, número 5, 2010

Portanto, este artigo não almejou propor uma solução para os problemas da globalização e do multiculturalismo, mas buscou contribuir para que fossem percebidas as limitações desses processos, bem como debater conceitos-chave nas relações internacionais que possam agregar valor aos estudos sobre as interações multiculturais e o fortalecimento do fenômeno global.

Por fim o trabalho buscou reforçar a importância do debate global acerca da cultura e de sua diversidade, e ampliar a percepção da participação cada vez maior de uma sociedade civil organizada internacionalmente e capaz de transpor limites geográficos e culturais para criar grupos de atividades em todas as áreas, enriquecendo assim, as discussões voltadas para o desenvolvimento mundial e para a promoção da paz.

\section{Referências bibliográficas}

\section{Livros:}

BIANCHI, Giorgio. In: BOBBIO, N., MATTEUCCI, N., PASQUINO, G. - Dicionário de Política. Brasília: UnB, 1986.

BRAVO, Gian Mario. In: BOBBIO, N., MATTEUCCI, N., PASQUINO, G. - Dicionário de Política. Brasília: UnB, 1986.

GIDDENS, Anthony. O mundo em descontrole: o que a globalização está fazendo de nós. Tradução de Maria Luiza X. de A. Borges. Rio de Janeiro: Record, 2000. p. 61-75. O mundo na era da globalização. Lisboa: Editorial Presença, 2002.

HELD, D. \& MCGREW, A. Prós e Contras da Globalização. Tradução de Vera Ribeiro. Rio de Janeiro: Jorge Zahar Ed., 2001.

HUNTINGTON, Samuel P. O choque das civilizações e a recomposição da ordem mundial. Tradução de M. H. C. Côrtes. Rio de Janeiro: Objetiva, 1997. 
Artigo original

Hegemonia - Revista Eletrônica de Relações Internacionais do Centro Universitário Unieuro ISSN: 1809-1261

UNIEURO, Brasília, número 5, 2010

KIYINDOU, Alain. Diversidade Cultural. In: AMBROSI, A., PEUGEOT, V., PIMIENTA, D. (org.) Desafios de Palavras: Enfoques Multiculturais sobre as Sociedades da Informação. França: 2005, C \& F Éditions.

McLAREN, Peter. Multiculturalismo crítico. $3^{\mathrm{a}}$ Edição. Tradução Bebel Orofino Schaefer. São Paulo: Cortez Editora, 2000. [Coleção Prospectiva]

SEMPRINI, Andrea. Multiculturalismo. Bauru: EDUSC, 1999.

TOURAINE, Alain. Poderemos viver juntos? Iguais e diferentes. Petrópolis: Vozes, 1997.

VESENTINI, José William. Novas Geopolíticas. 4a Edição. São Paulo: Contexto, 2005.

WEBER, Cynthia. International Relations Theory: A Critical Introduction. Second Edition. USA and Canada: Routledge, 2005. p. 151 - 176

Revistas e Periódicos:

A MARÉ da oposição. Época, São Paulo, v.3, n.124, p.118-119, 2 out. 2000.

FEATHERSTONE, Mike. Localismo, Globalismo e Identidade Cultural. In: Globalização e Fragmentação. Revista Sociedade e Estado. Volume XI no 1, Jan/Jun 1996. Brasília: UNB/ Departamento de Sociologia.

GÓMEZ, José María. Globalização da Política: Mitos, realidades e dilemas. Revista Praia Vermelha Estudos de Política e Teoria Social, 1, 1997. Rio de Janeiro: UFRJ/Programa de Pós-Graduação em Serviço Social.

NOGUEIRA, João Pontes. A guerra do Kosovo e a desintegração da Iugoslávia: notas sobre $a$ (re) construção do estado no fim do milênio. Revista Brasileira de Ciências Sociais, São Paulo, v. 15, n. 44, p. 143 - 160, out. 2000.

OBJETIVOS de Desenvolvimento do Milênio: Relatório Nacional de Acompanhamento. Coordenação: Instituto de Pesquisa Econômica Aplicada (Ipea) e Secretaria de Planejamento e Investimentos Estratégicos (SPI/MP); Supervisão: Grupo Técnico para o acompanhamento dos ODM. - Brasília: Ipea: MP, SPI, 2007.

SARDENBERG, Izalco. A queda do tirano dos Bálcãs. Época, São Paulo , v.3, n.125, p.9499, 9 out. 2000. 
Artigo original

Hegemonia - Revista Eletrônica de Relações Internacionais do Centro Universitário Unieuro ISSN: 1809-1261

UNIEURO, Brasília, número 5, 2010

SIQUEIRA, Ruy dos Santos. Multiculturalismo: o Olhar Cético da Comunidade AfroBrasileira. In: CASTRO, Gustavo. Revista ETHOS - Ano I - Número 2 - Jul/Dez 2000. Brasília: Ed SEPEB.

Consultas eletrônicas:

- http://educaterra.terra.com.br/voltaire/atualidade/iugoslavia.htm - HISTÓRIA Atualidade - Iugoslávia, a Destruição de uma Nação. Por Voltaire Schilling. Acessado em 8 de abril de 2008

- http://educaterra.terra.com.br/voltaire/mundo/servia.htm - HISTÓRIA - Mundo - A Sérvia e Kosovo. Por Voltaire Schilling. Acessado em 8 de abril de 2008

- http://www.un.org/ - Site Oficial das Nações Unidas. - Acessado em 20 de abril de 2008.

- http://vecam.org/article601.html: KIYINDOU, Alain. Diversidade Cultural. In: AMBROSI, A., PEUGEOT, V., PIMIENTA, D. (org.) Desafios de Palavras: Enfoques Multiculturais sobre as Sociedades da Informação. França: 2005, C \& F Éditions. 